\title{
Subjective Needs and Thoughts for the Treatment of Patients with Inflammatory Bowel Disease: Applying Q Methodology
}

\section{Yong Eun Park}

Inje University Haeundae Paik Hospital

Tae Oh Kim ( $\sim$ h00079@paik.ac.kr)

Inje University Haeundae Paik Hospital https://orcid.org/0000-0002-7359-1599

Jin Lee

Inje University Haeundae Paik Hospital

Jongha Park

Inje University Haeundae Paik Hospital

Joon Hyuk Choi

Inje University Haeundae Paik Hospital

Nae Yun Heo

Inje University Haeundae Paik Hospital

Seung Ha Park

Inje University Haeundae Paik Hospital

Won Sim Lee

BAYADA Home Health Care

\section{Research article}

Keywords: IBD patients, Q methodology, Quality of care

Posted Date: April 6th, 2020

DOI: https://doi.org/10.21203/rs.3.rs-19119/v1

License: (1) (1) This work is licensed under a Creative Commons Attribution 4.0 International License.

Read Full License 


\section{Abstract}

Background: Inflammatory bowel disease (IBD), including Crohn's disease (CD) and ulcerative colitis (UC), is a chronic inflammatory disorder of the gastrointestinal tract that requires lifetime management. Many studies have attempted to establish questionnaires and/or parameters to assess the quality of care for IBD patients. However, no study to date has investigated patients using Q-methodology, which is subjective and has been systematically studied, to identify and categorize their opinions and subjective thinking about their disease and treatment. Therefore, here we aimed to preliminarily examine Qmethodology to investigate the subjective thinking of IBD patients in Korea.

Methods: Q-methodology, a method of analyzing the subjectivity of questionnaire items, was examined in this study. At Haeundae Paik Hospital, 50 IBD patients were classified into 34 normalized statements using a 9-point scale with a normal distribution. The collected data were analyzed using the QUANL PC program.

Results: Using the Q-methodology, IBD patients were classified into type I, II, III, and IV treatment needs: medical staff-dependent, relationship-oriented, information-driven, and social awareness, respectively.

Conclusion: The subjective needs and thoughts about the treatment of IBD patients can be classified into four types. Our findings suggest that we can establish a systematic strategy for personalized care according to patient type.

\section{Background}

Awareness of the quality of care is increasing[1,2]. The increased incidence of inflammatory bowel disease (IBD), including chronic inflammatory gastrointestinal-impaired ulcerative colitis (UC) and Crohn's disease (CD)[3]. IBD is a recurring disease that leads to repeated hospitalizations and the need for long-term care[4], resulting in increased costs and frequent health care system utilization[5]. As a result, IBD patients need appropriate and standardized care from diagnosis to drug use, acute and outpatient care, and psychological and social aspects that are directly related to quality of life[6]. Several studies have reported on the quality of care in IBD patients[7-10]. To improve the quality of care of these patients, Donabedian's framework, which is composed of structure, process, and outcomes, can be used to set specific and measurable goals $[1,11]$. Based on this framework, various quality indicators for IBD patients have been reported. Among them, the International Consortium for Health Outcomes Measurement (ICHOM) quality outcome indicators is an indicator focused on the overall treatment outcome from diagnosis to palliative care or death[7]. However, these quality indicators focus on assessing the appropriateness of IBD patient care for healthcare providers.

In recent years, patient awareness has also increased. Many studies have emphasized the results reported by patients $[12,13]$, and the trend is gradually shifting to personalized treatments based on the "treat to target" paradigm[14, 15]. In addition to treatment goals, different approaches and treatment modalities are needed for each individual because each patient experiences treatment differently based 
on the disease course and their personal background[16, 17]. Therefore, understanding the patient's disease course and subjective thoughts will be key to improving quality of care. For this study, we adopted the Q methodology, which can systematically analyze subjectivity[18]. Subjectivity can be defined as one's thoughts, beliefs, values, and opinions about a particular phenomenon of interest of one or several people[19]. The Q methodology is used to analyze such subjectivity by analyzing subjective opinion through objectification using Q population theory and factor analysis[20]. To our knowledge, no study to date has systematically analyzed the subjective thoughts and perspectives of IBD patients using Q methodology. Therefore, this study aimed to identify the structural types and characteristics of the subjective and cognitive needs of treatment using Q methodology in IBD patients.

\section{Methods}

\section{Design: Q methodology}

Q methodology combines quantitative and qualitative techniques to study subjective phenomena in a systematic way[18, 21]. The overall Q methodology implementation process is shown in Figure 1.

\section{Concourse Development}

The concourse is defined as "the flow of communicability surrounding any topic" in "the ordinary conversation, commentary, and discourse of everyday life"[22]. The Q population is a collection of items collected for $Q$ research, the same as the concept of a total concourse of opinions shared within a culture. The $Q$ population is mainly used for literature research or in-depth interviews[23]. The subjects chosen for in-depth interviews for the Q population are expected to have the same and different views[24]. As the concourse must capture the range of participant experiences (ex. first experience of diagnosis), a variety

of sources are used to develop the concourse statements.

We enrolled IBD patients, including those with UC and CD diagnosed with clinical, endoscopic, histopathologic, and radiologic findings, in this study[21, 25]. In-depth interviews and focus family interviews were conducted by BAYADA Home Health Care Inc. to select a group in November 2016 for the Q population. In-depth interviews were conducted of 8 patients ( 4 males, 4 females; 7 with CD, 1 with UC) and focus family group interviews were conducted of 3 patients and 4 of their family members for recognition categorization (Figure 1).

\section{Q sample and Q statement}

Based on previous interviews and a literature research, the Q population consisted of 274 statements. To select Q samples, the 274 statements were repeatedly read several times to identify their common values and meanings and classified into the following 10 categories. Related items were as follows: diagnostic process, medical care team, diagnosis-treatment process (discomfort points), contact points, affected events, disease management efforts, social efforts, role of medical personnel, questions, negative experiences, and perceptions. Thirty-four finalized Q samples were selected for category statements of 
the same (positive), intermediate (neutral), or different (negative) meanings. Reliability was verified using a pretest on two selected researchers. On the pretest, both subjects were able to complete the $\mathrm{Q}$ sorting work within 30 minutes, and neither answered that the contents were difficult. Q cards and distribution map were subsequently produced (Figure 1).

\section{P sample}

The P sample refers to respondents or subjects who actually participate in the Q sorting (i.e., Q sorter)[20]. In Q methodology, people are variables and items refer to samples, so the number of subjects is sufficient to generate factors and compare them between factors[20].. Based on this theoretical basis, this study constructed a $\mathrm{P}$ sample of 53 patients who visited the outpatient department of Haeundae Paik Hospital and agreed to participate in the study. This study was performed in accordance with the ethical guidelines of the 1975 Declaration of Helsinki and approved by the Institutional Review Board of Haeundae Paik Hospital.

\section{Q sorting procedure}

We conducted a brief survey and Q sorting of 53 outpatients from February to March 2019 at Haeundae Paik Hospital, Inje University College of Medicine, Busan, Korea. Three patients did not understand the Q sorting and were excluded due to insufficient analysis, resulting in a total of 50 patients. Q sorting refers to the process by which a respondent sorts $Q$ samples and assigns a score to each[20]. The $Q$ sorting process according to the forced normal distribution method is prepared by a Q sample distribution with a 9-point scale (Figure 2, Q-grid). The two most negative (disagree) cards are placed at (-4), and the rest of the cards are arranged in order of importance $(-3) \rightarrow(-1)$. The two most positive (agree) cards are placed in position at $(+4)$, and the remaining cards are ranked according to importance $(+3)->(+1)$ arranged in order. The neutral cards are placed in the $(0)$ position, and the remaining cards are arranged in the remaining (+) or (-) space according to their importance. Finally, a simple survey was conducted with the reason for the card selection.

\section{Baseline patient characteristics}

The baseline characteristics of the patients were obtained from a short survey and included patient demographics, academic achievement, religion, marital status, occupation, time to diagnosis, number of hospitals to diagnosis, treatment duration, and general condition.

\section{Data analysis}

In the analysis of the data obtained through the $\mathrm{Q}$ sample classification process, the most negative questions were scored as -4 (1 point), -3 ( 2 points), -2 (3 points), -1 (4 points), 0 (5 points), +1 (6 points), +2 (7 points), +3 (8 points), and +4 (9 points) to be coded (Figure 2 ). The $50 \mathrm{Q}$ sorted data were analyzed using the QUANL PC program (version 1.2), while the $\mathrm{Q}$ factor analysis was performed using principle component factor analysis (varimax), and the results were used as important data for identifying the characteristics of each target type. 
Variables are expressed as median (interquartile range [IQR]) or $n(\%)$. The baseline characteristics were compared using independent Student's t-test (or the Mann-Whitney test) for continuous variables and the $\chi^{2}$ test (or Fisher's exact test) for categorical variables as appropriate. The baseline data were analyzed using SPSS software (version 25.0; IBM Corp., Armonk, NY, USA). P values $<0.05$ were considered statistically significant.

\section{Results}

\section{Baseline characteristics of the study participants}

The baseline characteristics of the 50 IBD patients who participated in the short survey and Q sorting are summarized in Table 1. A total of 50 patients with CD $(n=32)$ and UC $(n=18)$ visited the outpatient IBD clinic from February to March 2019 and participated in the study. The median patient age was 27 years (IQR, 22-34 years); $37.0 \%$ of them were male, 70\% were unmarried, and CD patients showed a significantly higher unmarried rate $(81.3 \%$ vs. $50.0 \% ; P=0.021)$. There were no significant differences between the $\mathrm{CD}$ and $\mathrm{UC}$ groups in the other baseline characteristics.

More than half of the subjects were highly educated (university graduation, $52.0 \%$ ), while $38 \%$ were students. Most participants did not declare a religion (78.0\%). Most had been diagnosed with IBD less than 1 year prior $(60.0 \%)$. In addition, $56 \%$ of the patients had visited a mean 2 different clinics/hospitals before coming to our hospital; the treatment duration was generally $3-5$ years (34.0\%). This finding indicates that the treatment period is long but that the diagnosis is made relatively late. Most patients reported that their overall condition was relatively good (Table 1 ).

\section{Formation and correlation of Q type}

We evaluated the Q types of IBD patients for subjective phenomena. Four types accounted for $46.5 \%$ of the total variance: Types $1,2,3$, and 4 showed $28 \%, 9.5 \%, 5 \%$, and $4.1 \%$, respectively. The first type explained the attitude of IBD patients about their care (Table 2). The correlations among the 4 types of IBD patients are summarized in Table 3. Moderate correlation was seen in the degree of similarity among types $(r=0.32-0.64)$, indicating that the types are relatively independent (Table 3$)$.

\section{Characteristics of the four subjective treatment need types}

According to $34 \mathrm{Q}$ statements (Table 4), four types of subjectivity regarding the treatment in IBD patients were classified. Tables $\mathbf{4}$ and $\mathbf{5}$ show the results of each type of analysis of the standard score (Z-score) of the representative statements. Higher factor weights indicate more typical characteristics of the type.

\section{Type 1: Medial staff dependence type}

A total of 20 patients ( $40 \%$ ) were classified as type 1. Patients of this type tended to show strong beliefs and dependence on medical staff. There were 15 men (75.0\%); the mean age was 25 years (IQR, 20-38 years). The percentage of highly educated individuals was lower than that of the other types $(45.0 \% \mathrm{vs}$. 
$60.0 \%$ vs. $54.5 \%$ vs. $55.6 \% ; P=0.611)$. Compared to other types, the proportion of patients diagnosed within 1 year was higher ( $65 \%$ vs. $60 \%$ vs. $54.5 \%$ vs. $55.6 \% ; P=0.385)$ (Supplementary Table 1).

Q statements with a Z-score greater than 1.0 included: "The professionalism of the medical staff is the expertise of the disease and the experience of the patient."; "I would like to help people who have similar symptoms in the future be diagnosed quickly."; "Staff should basically have an attitude of understanding and respond to the patient."; "It is helpful to say that rare and incurable diseases are used to distinguish diseases and that there is no problem if you are managed well."; "The medical staff is very valuable to my overcoming my situation and is more important than a family living together."; and "I think I should take care of myself because my doctor always talks to me in a positive way."

However, they most often disagreed with the following statements: "What is diagnosed and immediately educated is neither memorable nor helpful."; "Nurses are for hospitals, not for patients."; "I went to the hospital seminar only once or twice, but it does not help much."; "When I go to a hospital seminar, it does not help because it seems like only the same attendees talk."; and "It is not easy to meet medical staff working for patients." (Table 5).

Common consent items for this type of patient are important for trust in the medical team and the belief that the condition will improve if the hospital provides treatment. They are encouraged by positive comments from the medical staff and strongly want to help treat patients with similar symptoms who have not been properly diagnosed but have received wrong folk remedies. Hospital seminars are also helpful because patients can meet people with similar symptoms while hearing various lectures.

\section{Type 2: Relationship-oriented type}

A total of 10 patients (20\%) were classified as type 2 . They value the professionalism of the medical staff, but they think they should be aware of the disease and know how to manage it themselves. They are also strongly burdened by the disease itself, the related pain, and the concerns of their family and neighbors. Patients of this type were $90 \%$ male and younger than those of other types (mean age, 24 years). Sixty percent of the patients of this type were the most highly educated, with college degrees $(P=$ $0.611)$, and most were single $(90.0 \%)$. Seventy percent of these patients had $C D$, and more patients from this group were diagnosed more than 3 years prior than the other types (type 1, 2, 3, and 4; $15.0 \%$ vs. $30.0 \%$ vs. $9.1 \%$ vs. $0 \% ; P=0.385)$. In addition, many patients tended to think that their overall condition was poor (type $1,2,3$, and $4 ; 5.0 \%$ vs. $20 \%$ vs. $9.1 \%$ vs. $0 \% ; P=0.496$ ) (Supplementary Table 1 ). This finding indicates that they are more likely to believe that they should manage the disease on their own, expecting to consult the medical staff as they experience various courses of the disease during the treatment period.

The Q statements with a Z-score > 1.0 include the following: "I want to know how to manage patients who have had long remission periods."; "The professionalism of the medical staff is the expertise of the disease and the experience of the patient."; "I do not want to make my family feel uncomfortable because of me."; "Staff members should be understanding and responsive to patients."; "People without a sick 
person in their family do not understand the pain."; and "It is difficult to handle an unpredictable and difficult-to-treat disease."

The patients most often disagreed with following statements: "It is helpful to say that rare and incurable diseases are used to distinguish diseases, and that there is no problem if you manage it well."; "It was too difficult to find a specialist for IBD at nearby hospitals and local clinics."; "Just do what the doctors tell you to do."; "Nurses are for hospitals, not for patients."; and "I found an IBD hospital on the internet."

\section{(Table 5).}

The patients with the highest factor weights were type 2 and said that those who did not experience the disease could not understand the pain and the family's concerns; one stated that he did not want his family to feel uncomfortable because of him. He also said that people are not familiar with CD, which makes it difficult for him to obtain the time and financial means required to obtain proper treatment.

\section{Type 3: Information-driven type}

A total of 11 patients (22\%) were classified as type 3 . Rather than being affected by the experiences or circumstances of other patients, they want to be provided with information and health care that is helpful to them. Compared to other types, they strongly value the need for clinicians to answer questions when they need them. However, they have a strong desire to know about their disease and how to manage a worsening situation. This group was composed of a higher rate of married people than the other types (type $1,2,3$, and $4 ; 35 \%$ vs. $10 \%$ vs. $45.5 \%$ vs. $22.2 \%$; $P=0.301$ ). $C D$, which can show various disease courses and complications, was seen in $80 \%$ of affected patients, who made many hospital visits before being diagnosed (Supplementary Table 1).

The Q statements with a Z-score > 1.0 included: "The professionalism of the medical staff is the expertise of the disease and the experience of the patient."; "I would like to help people who have similar symptoms in the future be diagnosed quickly.; ; "I should understand my disease and find ways to manage it."; "To maintain an ordinary life, we must constantly fight ourselves."; "It was too difficult to find a specialist for IBD at a nearby hospital or clinic."; "I would like to have access to a medical staff member who can answer my questions when I have them."; and "Staff members should be understanding and responsive to patients."

The patients most often disagreed with the following statements; "The medical staff is a very valuable person in overcoming my situation and more important than a family member.; "Stories of people with similar experiences are comforting."; "When I go to a hospital seminar, it does not help because it seems like the same attendees talk."; "Knowledge of the disease does not help."; and "What is diagnosed and immediately educated is neither memorable nor helpful." (Table 5).

Commonly mentioned statements of this type of patient were the importance of medical professionalism and disease knowledge as well as the importance of knowing themselves. Most patients of this type said 
in the survey that they wanted to find good information, understand their disease, and find ways to manage it.

\section{Type 4: Social awareness type}

A total of 9 patients (18\%) were classified as type 4 , a type that calls for changes in the reality and social awareness that require not only basic medical expertise but also efficient access to specialized hospitals and medical staff. These patients value knowledge, education, and seminars and think that nurses should be the people who actively care for affected patients. Of the four types, the average age was the highest (type 1, 2, 3, and 4; 25 years vs. 24 years vs. 28 years vs. 31 years; $P=0.559$ ), and participants had the highest employment rate. In addition, patients who had been treated for more than 10 years accounted for $33 \%$ of this type (type $1,2,3$, and $4 ; 0 \%$ vs. $20 \%$ vs. $18.2 \%$ vs. $33.3 \% ; P=0.584$ ) (Supplementary Table 1).

The Q statements with a Z-score > 1.0 included: "The professionalism of the medical staff is the expertise of the disease and the experience of the patient."; "It was too difficult to find a specialist for IBD at a nearby hospital or clinic."; "Social awareness of rare diseases should change."; and "Staff members should be understanding and responsive to patients."

However, they most often disagreed with the following statements: "Knowledge of the disease does not help."; "I went to the hospital seminar only once or twice, but it does not help much."; "If I ask the nurse any questions, he or she says I should talk to a doctor."; "I found an IBD hospital on the internet."; and "Nurses work for hospitals, not for patients." (Table 5).

Some patients had a hard time understanding their exact diagnosis and mentioned that local hospitals and clinics are not well aware of the disease and that it is difficult to find professional medical staff. Another patient emphasized the need for people's consideration of and attention to IBD patients due to changes in social awareness. Some also said that they received better information through seminars with medical staff since there was a lot of wrong information on the internet.

\section{Consensus between views}

The four commonly agreed statements of subjectivity in relation to disease-related attitudes in IBD patients are: "The professionalism of the medical staff is the expertise of the disease and the experience of the patient"; and "Staff members should be understanding and responsive to patients.". However, all types of patients disagreed with the following statement: "Knowledge of the disease does not help."

\section{Discussion}

Despite advances in the treatment of IBD[26] and improvements in healthcare quality, IBD patients still struggle with treatment, complicated management, and quality of life. Therefore, it is important that we not only to improve the quality of care but also to understand patient perceptions of the disease and treatment process to provide personalized care. Our study is an objective analysis using Q methodology 
of what patients think of the disease and what words and processes were helpful and difficult while receiving treatment. Our findings showed four types of IBD patients, including medical staff-dependent, relationship-oriented, information-driven, and social awareness, with slightly different values regarding what patients need.

With the increasing awareness and interest in IBD due to chronic care diseases with a large number of young patients, efforts to measure the quality of care from the patient perspective are also increasing[2, 12 ,27]. Soares et al.[12] reported the validation of the Portuguese version of a questionnaire to measure quality of care through the eyes of patients with inflammatory bowel disease (QUOTE-IBD). They analyzed 9 dimensions of the QUOTE-IBD: total care, accessibility, accommodation, autonomy, competence, continuity of care, cost, courtesy, and information. Most items had reliable results; however, they reported no significant difference in disease type or quality of life associated with activity or health. Therefore, more research is needed because of the lack of tools available to evaluate the quality of care from the patient perspective. Thus, it was meaningful to analyze subjectivity from the patient perspective in this study.

In our study, many type 1 patients (medical staff-dependent) thought that they should trust the medical staff and follow their instructions. Considering the fact that many patients were diagnosed less than 1 year prior to this study, their thoughts and perspectives may vary depending on the length of time since diagnosis. In type 2 patients (relationship-oriented), the burden on family interests and suffering was greater than that of other types. One patient said that even though the pain was not caused by IBD, it was considered a symptom of IBD and did was not treated well. It is difficult to explain the disease, so even family members do not understand the patient's condition well. Through this study, we found that the families of patients also require education and mental support and communication. Type 3 patients (information-driven) showed similar statements as those of types I and II. Medical expertise, willingness to help, and unwillingness to be a burden on the family were similar, but compared to other types, they tended to have a strong desire to solve, manage, and understand the disease on their own. This type of patient wanted to know how to manage the disease so that it would not worsen and how they could control it, especially with food choices. Thus, detailed explanations and options even during the drug decision process can be helpful for these patients, and counseling with nutritionists and multidisciplinary teams can be of great help. Type 4 patients (social awareness) tend to pay attention to social awareness, as this type includes several long-term patients who have been treated for more than 10 years. In fact, IBD remains recognized as a rare disease in Korea, and it is often seen as embarrassing for workers and colleagues around them to know about the condition. Therefore, most patients do not talk about the disease because it is difficult to explain. To change the perception of IBD, it is necessary to publicize disease information and show that good management can lead to a life without difficulties. However, social efforts are still lacking. Therefore, it is necessary to first explore ways to help patients with IBD from the hospital side, such as making toilets and forming multi-disciplinary teams.

Our study, the first using Q methodology in IBD patients, shows strong advantages in terms of analyzing the subjectivity of patients divided into four types. However, our study had several limitations. First, only a 
relatively small number of outpatients were enrolled, which can lead to selection bias. However, because we wanted to observe quality of care, we think that only outpatients could be compared in a consistent situation. However, further studies are needed with more patients, including inpatients. Second, we could not interview all patients and their related family members in depth. Although in-depth interviews were conducted for $\mathrm{Q}$ sampling, the number of participants was small. Therefore, further well-designed studies with large populations are needed in the future.

\section{Conclusions}

In summary, here we used Q methodology to divide the subjective thoughts of IBD patients into four types: medical staff-dependent, relationship-oriented, information-driven, and social awareness. We realized in this study that patients wanted expertise of the medical staff, wanted to learn about the disease, and were helped by seminars. These results will provide basic information to help patients understand and provide care from the perspective of IBD patients.

\section{Abbreviations}

IBD, inflammatory bowel disease; GI, gastrointestinal; UC, ulcerative colitis; CD, Crohn's disease; IQR, interquartile range

\section{Declarations}

Ethics approval and consent to participate The study protocol was approved by the ethical guidelines of the 1975 Declaration of Helsinki and approved by the Institutional Review Board of Haeundae Paik Hospital. (IRB number \# 2018-08-026-004). This study was conducted based on a questionnaire, and there was no reason to estimate the subject's consent, and even if the consent was exempted, the risk to the subject was extremely low, and the subject consent exemption was granted. Consent for Publication Not applicable Availability of data and material The data sets used and/or analyzed during the current study are available from the corresponding author on reasonable request. Competing interests The authors declare that they have no competing interests. Funding The authors declare that no funding was received for the present study Authors' contributions Study concepts: Tae Oh Kim. Study design: Tae Oh Kim. Data acquisition: Yong Eun Park, Jin Lee, Jongha Park, Joon Hyuk Choi, Nae Yun Heo, Seung Ha Park, Tae Oh Kim. Data analysis and interpretation: Yong Eun Park, Won Sim Lee. Manuscript preparation: Yong Eun Park. Manuscript editing: Yong Eun Park, Won Sim Lee, Tae Oh Kim. Manuscript review: Tae Oh Kim. All authors have read and approved the manuscript. Acknowledgements We wish to express our sincere gratitude for the valuable assistance of Yoon Kyoung Lee and Won Sim Lee of the Education, R\&D Team / BAYADA Home Health Care Inc. Author details 1Division of Gastroenterology, Department of Internal Medicine, Inje University College of Medicine, Haeundae Paik Hospital, Busan, Republic of Korea 2Clinical Manager, BAYADA Home Health Care Inc. Seoul, Republic of Korea

\section{References}


1. Ye BD, Travis S: Improving the quality of care for inflammatory bowel disease. Intestinal research 2019, 17(1):45-53.

2. Egberg MD, Gulati AS, Gellad ZF, Melmed GY, Kappelman MD: Improving Quality in the Care of Patients with Inflammatory Bowel Diseases. Inflammatory bowel diseases 2018, 24(8):1660-1669.

3. Kwak MS, Cha JM, Lee HH, Choi YS, Seo SI, Ko KJ, Park DI, Kim SH, Kim TJ: Emerging trends of inflammatory bowel disease in South Korea: A nationwide population-based study. Journal of gastroenterology and hepatology 2019, 34(6):1018-1026.

4. Kappelman MD, Palmer L, Boyle BM, Rubin DT: Quality of care in inflammatory bowel disease: a review and discussion. Inflammatory bowel diseases 2010, 16(1):125-133.

5. Burisch J, Jess T, Martinato M, Lakatos PL: The burden of inflammatory bowel disease in Europe. Journal of Crohn's \& colitis 2013, 7(4):322-337.

6. Berry SK, Siegel CA, Melmed GY: Quality Improvement Initiatives in Inflammatory Bowel Disease. Current gastroenterology reports 2017, 19(8):41.

7. Berry SK, Melmed GY: Quality indicators in inflammatory bowel disease. Intestinal research 2018, 16(1):43-47.

8. Melmed GY, Siegel CA, Spiegel BM, Allen JI, Cima R, Colombel JF, Dassopoulos T, Denson LA, DudleyBrown S, Garb A et al: Quality indicators for inflammatory bowel disease: development of process and outcome measures. Inflammatory bowel diseases 2013, 19(3):662-668.

9. Calvet X, Panes J, Alfaro N, Hinojosa J, Sicilia B, Gallego M, Perez I, Lazaro y de Mercado P, Gomollon F, Aldeguera $X$ et al: Delphi consensus statement: Quality Indicators for Inflammatory Bowel Disease Comprehensive Care Units. Journal of Crohn's \& colitis 2014, 8(3):240-251.

10. Nguyen GC, Devlin SM, Afif W, Bressler B, Gruchy SE, Kaplan GG, Oliveira L, Plamondon S, Seow CH, Williams $\mathrm{C}$ et al: Defining quality indicators for best-practice management of inflammatory bowel disease in Canada. Canadian journal of gastroenterology \& hepatology 2014, 28(5):275-285.

11. Donabedian A: The quality of care. How can it be assessed? Jama 1988, 260(12):1743-1748.

12. Soares JB, Nogueira MC, Fernandes D, Goncalves BM, Goncalves R: Validation of the Portuguese version of a questionnaire to measure Quality of Care Through the Eyes of Patients with Inflammatory Bowel Disease (QUOTE-IBD). European journal of gastroenterology \& hepatology 2015, 27(12):1409-1417.

13. Pittet V, Vaucher C, Froehlich F, Maillard MH, Michetti P: Patient-reported healthcare expectations in inflammatory bowel diseases. PloS one 2018, 13(5):e0197351.

14. Peyrin-Biroulet L, Sandborn W, Sands BE, Reinisch W, Bemelman W, Bryant RV, D'Haens G, Dotan I, Dubinsky M, Feagan B et al: Selecting Therapeutic Targets in Inflammatory Bowel Disease (STRIDE): Determining Therapeutic Goals for Treat-to-Target. The American journal of gastroenterology 2015, 110(9):1324-1338.

15. Bossuyt P, Vermeire S: Treat to Target in Inflammatory Bowel Disease. Current treatment options in gastroenterology 2016, 14(1):61-72. 
16. Ruel J, Ruane D, Mehandru S, Gower-Rousseau C, Colombel JF: IBD across the age spectrum: is it the same disease? Nature reviews Gastroenterology \& hepatology 2014, 11(2):88-98.

17. Burisch J, Kiudelis G, Kupcinskas L, Kievit HAL, Andersen KW, Andersen V: Natural disease course of Crohn's disease during the first 5 years after diagnosis in a European population-based inception cohort: an Epi-IBD study. 2018.

18. Gallagher K, Porock D: The use of interviews in Q methodology: card content analysis. Nursing research 2010, 59(4):295-300.

19. Paige JB, Morin KH: Q-Sample Construction: A Critical Step for a Q-Methodological Study. Western journal of nursing research 2016, 38(1):96-110.

20. Kim H-K: Q methodology: Philosophy, theories, analysis, and application. Seoul: Communication Books 2008:78-191.

21. Choi CH, Jung SA, Lee BI, Lee KM, Kim JS, Han DS: [Diagnostic guideline of ulcerative colitis]. The Korean journal of gastroenterology = Taehan Sohwagi Hakhoe chi 2009, 53(3):145-160.

22. Brown SR: A primer on Q methodology. Operant subjectivity 1993, 16(3/4):91-138.

23. Ah CJ, Han KB: Recognition on Suicidal Intent of the Elderly among Caregivers: A Q-Methodological Application. Korean Journal of Adult Nursing 2014, 26(5).

24. Park K-S: A study on the subjective perception patterns of social workers to corporate philanthropy in social work field. Korean Jounal of Social Welfare 2009, 61(4):109-136.

25. Ye BD, Jang BI, Jeen YT, Lee KM, Kim JS, Yang SK: [Diagnostic guideline of Crohn's disease]. The Korean journal of gastroenterology = Taehan Sohwagi Hakhoe chi 2009, 53(3):161-176.

26. Brown SR: Political subjectivity: Applications of Q methodology in political science: Yale University Press; 1980.

27. van der Eijk I, Sixma H, Smeets T, Veloso FT, Odes S, Montague S, Fornaciari G, Moum B, Stockbrugger R, Russel M: Quality of health care in inflammatory bowel disease: development of a reliable questionnaire (QUOTE-IBD) and first results. The American journal of gastroenterology 2001, 96(12):3329-3336.

\section{Tables}

Table 1. Demographics characteristics $(n=50)$ 


\begin{tabular}{|c|c|c|c|c|}
\hline Variables & Total $(n=50)$ & $\mathrm{CD}(\mathrm{n}=32,64.0 \%)$ & $\mathrm{UC}(\mathrm{n}=18,36.0 \%)$ & $P$-value \\
\hline Male sex & $37(74.0)$ & $24(64.9)$ & $13(35.1)$ & 0.830 \\
\hline Age & $27(22-34)$ & $31(21-39)$ & $26(22-32)$ & 0.191 \\
\hline Academic achievement & & & & 0.692 \\
\hline middle School graduation & $3(6.0)$ & $1(3.1)$ & $2(11.1)$ & \\
\hline high school graduation & $17(34.0)$ & $11(34.4)$ & $6(33.3)$ & \\
\hline College graduate & $4(8.0)$ & $3(9.4)$ & $1(5.6)$ & \\
\hline University graduation & $26(52.0)$ & $17(53.1)$ & $9(50.0)$ & \\
\hline Religion & & & & 0.165 \\
\hline atheism & $39(78.0)$ & $28(87.5)$ & $11(61.1)$ & \\
\hline Buddhism & $5(10.0)$ & $2(6.3)$ & $3(16.7)$ & \\
\hline Christian & $4(8.0)$ & $1(3.1)$ & $3(16.7)$ & \\
\hline Catholic & $2(4.0)$ & $1(3.1)$ & $1(5.6)$ & \\
\hline Marital status & & & & 0.021 \\
\hline single & $35(70.0)$ & $26(81.3)$ & $9(50.0)$ & \\
\hline married & $15(30.0)$ & $6(18.8)$ & $9(50.0)$ & \\
\hline Occupation* & & & & 0.660 \\
\hline student & $19(38.0)$ & $13(40.6)$ & $6(33.3)$ & \\
\hline inoccupation & $7(14.0)$ & $5(15.6)$ & $2(11.1)$ & \\
\hline Professionst & $6(12.0)$ & $3(9.4)$ & $3(16.7)$ & \\
\hline Office workersł & $12(24.0)$ & $8(25.0)$ & $4(22.2)$ & \\
\hline 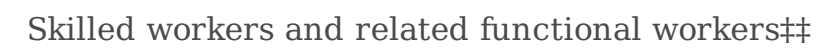 & $3(6.0)$ & $2(6.3)$ & $1(5.6)$ & \\
\hline Sales Employees & $1(2.0)$ & $0(0)$ & $1(5.6)$ & \\
\hline Public officer & $1(2.0)$ & $0(0)$ & $1(5.6)$ & \\
\hline Temporary worker & $1(2.0)$ & $1(3.1)$ & $0(0)$ & \\
\hline Time to diagnosis & & & & 0.524 \\
\hline$<1$ year & $30(60.0)$ & $18(56.3)$ & $12(66.7)$ & \\
\hline $1 \sim 3$ years & $13(26.0)$ & $10(31.3)$ & $3(16.7)$ & \\
\hline 3years & $7(14.0)$ & $4(12.5)$ & $3(16.7)$ & \\
\hline Number of hospital to diagnosis & & & & 0.142 \\
\hline 1 & $6(12.0)$ & $5(15.6)$ & $1(5.6)$ & \\
\hline 2 & $28(56.0)$ & $14(43.8)$ & $14(77.8)$ & \\
\hline 3 & $10(20.0)$ & $8(25.0)$ & $2(11.1)$ & \\
\hline 4 & $6(12.0)$ & $5(15.6)$ & $1(5.6)$ & \\
\hline Duration of treatment & & & & 0.341 \\
\hline$<1$ year & $5(10.0)$ & $3(9.4)$ & $2(11.1)$ & \\
\hline $1 \sim 3$ years & $6(12.0)$ & $2(6.3)$ & $4(22.2)$ & \\
\hline 3 5years & $17(34.0)$ & $10(31.3)$ & $7(38.9)$ & \\
\hline 5 10years & $15(30.0)$ & $12(37.5)$ & $3(16.7)$ & \\
\hline$\geq 10$ years & $7(14.0)$ & $5(15.6)$ & $2(11.1)$ & \\
\hline General condition & & & & 0.147 \\
\hline Well-being & $9(18.0)$ & $8(25.0)$ & $1(5.6)$ & \\
\hline Good & $23(46.0)$ & $15(46.9)$ & $8(44.4)$ & \\
\hline usually & $14(28.0)$ & $8(25.0)$ & $6(33.3)$ & \\
\hline Bad & $4(8.0)$ & $1(3.1)$ & $3(16.7)$ & \\
\hline Very-bad & $0(0)$ & $0(0)$ & $0(0)$ & \\
\hline
\end{tabular}

Data are expressed as median (interquartile range, IQR) or $\mathrm{n}(\%)$. P-value for comparing patients with CD and UC patients.

UC, Ulcerative colitis; CD, Crohn's disease; 
*Occupation groups are classified according to "Korean standard classification of occupations 7th edition"

†Professions; pharmacist, researcher, shipyard, teacher, architect. ¥Office workers; bank clerk, office worker, office worker, service industry $\ddagger \ddagger S k i l l e d$ workers and related functional workers; electric power production; manufacturing industry

Table 2. Eigen Values, Variance, and cumulative percentage ( $\mathrm{N}=50)$

\begin{tabular}{lllll}
\hline & Type 1 & Type 2 & Type 3 & Type 4 \\
\hline Eigen value & 13.9838 & 4.7493 & 2.4780 & 2.0484 \\
Variance (\%) & 0.2797 & 0.0950 & 0.0496 & 0.0410 \\
Cumulative variance & 0.2797 & 0.3747 & 0.4242 & 0.4652 \\
\hline
\end{tabular}

Table 3. Correlation among Types

\begin{tabular}{lllll}
\hline & Type 1 & Type 2 & Type 3 & Type 4 \\
\hline Type 1 & 1.000 & & & \\
Type 2 & 0.318 & 1.000 & & \\
Type 3 & 0.437 & 0.536 & 1.000 & \\
Type 4 & 0.639 & 0.565 & 0.573 & 1.000 \\
\hline
\end{tabular}

Table 4. Q-statements and Z-scores according to types 
1. I would like to help people who have similar symptoms in the future be diagnosed quickly.

2. It was too difficult to find a specialist for IBD at nearby hospital and clinic.

3. I found an IBD hospital on the Internet.

4. The medical staff is very valuable person in overcoming my situation and more important than a family member.

5. Just do what the doctors tell you to do.

6. Nurses are for hospitals, not for patients.

7. When I get a referral from another department, it's hard to explain my condition as if I came to the hospital again.

8. The professionalism of the medical staff is the expertise of the disease and the experience of the patient.

9. Staff members should be understanding and responsive to patients.

10. I would like to listen to the stories of people who have overcome the problems of having a job.

11. What is diagnosed and immediately educated is neither memorable nor helpful.

12. If I ask the nurse any questions, he or she says I should talk to a doctor.

13. If I have any questions, I can browse the Internet like a habit, but it's hard to find information that's right for me.

14. I think I should take care of myself because my doctor always talks to me in a positive way.

15. People without a sick person in their family do not understand the pain.

16. I went to the hospital seminar only once or twice, but it does not help much.

17. Knowledge of the disease does not help.

18. I would like to have a medical staff who can answer my questions when I have them.

19. I want disease education and counseling when I want to receive it.

20. Stories of people with similar experiences are comforting.

21. It is helpful to say that rare and incurable diseases are used to distinguish diseases, and that there is no problem if you manage it well.

22. I should understand my disease and find ways to manage it.

23. I don't want to make my family feel uncomfortable because of me.

24. If I see a patient worse than me, I am determined not to be like that.

25. To maintain an ordinary life, we must constantly fight ourselves.

26. It is difficult to handle an unpredictable and difficult-totreat disease.

27. When I go to a hospital seminar, it doesn't help because it seems like only the same attendees talk.

28. At first, I can't hear anything no matter what anyone says, but there are times when I get curious and information comes to my ears.

29. There is hope when I hear about new treatments.

30. Social awareness of rare diseases should change.

31. We should continue to campaign for the understanding of IBD and social considerations.

\begin{tabular}{|c|c|c|c|}
\hline $\begin{array}{l}\text { Type } \\
1\end{array}$ & $\begin{array}{l}\text { Type } \\
2\end{array}$ & $\begin{array}{l}\text { Type } \\
3\end{array}$ & $\begin{array}{l}\text { Type } \\
4\end{array}$ \\
\hline 1.52 & 0.71 & 1.70 & 0.92 \\
\hline 0.01 & -1.09 & 1.24 & 1.89 \\
\hline $\begin{array}{l}-0.59 \\
1.31\end{array}$ & $\begin{array}{l}-1.66 \\
0.32\end{array}$ & $\begin{array}{l}-0.67 \\
-1.10\end{array}$ & $\begin{array}{l}-1.56 \\
0.52\end{array}$ \\
\hline $\begin{array}{l}0.94 \\
-1.37 \\
-0.97\end{array}$ & $\begin{array}{l}-1.56 \\
-1.57 \\
0.40\end{array}$ & $\begin{array}{l}-0.63 \\
0.09 \\
0.46\end{array}$ & $\begin{array}{l}-0.63 \\
-1.65 \\
-0.37\end{array}$ \\
\hline 1.63 & 1.71 & 2.04 & 1.95 \\
\hline 1.39 & 1.60 & 1.04 & 1.20 \\
\hline 0.06 & 0.36 & 0.04 & 0.26 \\
\hline-1.03 & -0.50 & -1.52 & -1.84 \\
\hline-1.09 & -0.68 & -0.49 & -1.31 \\
\hline 0.08 & -0.21 & -0.42 & 0.22 \\
\hline 1.26 & -0.49 & 0.07 & 0.44 \\
\hline-0.34 & 1.56 & -0.24 & 0.70 \\
\hline-1.45 & -0.76 & -0.51 & -1.26 \\
\hline $\begin{array}{l}-1.71 \\
0.98\end{array}$ & $\begin{array}{l}-1.12 \\
-0.24\end{array}$ & $\begin{array}{l}-1.39 \\
1.07\end{array}$ & $\begin{array}{l}-1.18 \\
0.95\end{array}$ \\
\hline-0.02 & 0.05 & -0.87 & -0.02 \\
\hline $\begin{array}{l}0.68 \\
1.32\end{array}$ & $\begin{array}{l}-0.02 \\
-1.08\end{array}$ & $\begin{array}{l}-1.16 \\
-0.83\end{array}$ & $\begin{array}{l}0.03 \\
-0.22\end{array}$ \\
\hline 0.84 & 1.20 & 1.53 & 0.73 \\
\hline-0.14 & 1.65 & 1.82 & 0.93 \\
\hline-0.26 & 0.15 & 1.34 & -0.99 \\
\hline 0.92 & 0.63 & 1.34 & 0.26 \\
\hline-1.08 & 1.25 & 0.31 & -0.50 \\
\hline-1.62 & -0.95 & -1.33 & -1.46 \\
\hline 0.07 & -0.85 & -0.79 & -0.69 \\
\hline $\begin{array}{l}0.77 \\
0.14 \\
-0.25\end{array}$ & $\begin{array}{l}-0.31 \\
0.48 \\
-0.02\end{array}$ & $\begin{array}{l}0.23 \\
-0.66 \\
-0.50\end{array}$ & $\begin{array}{l}0.82 \\
1.22 \\
0.70\end{array}$ \\
\hline
\end{tabular}


32. I feel energized when I have a medical staff who looks me

0.22

0.03

$-0.29$

$-0.62$ in the eye and asks me questions.

33. It is not easy to meet medical staff working for patients.

$\begin{array}{lll}-1.62 & -0.86 & -0.73\end{array}$

0.36

34. I want to know how to manage patients who have had $-0.621 .85$ long remission periods.

Table 5. Q-statements and Z-scores by subjective need type 


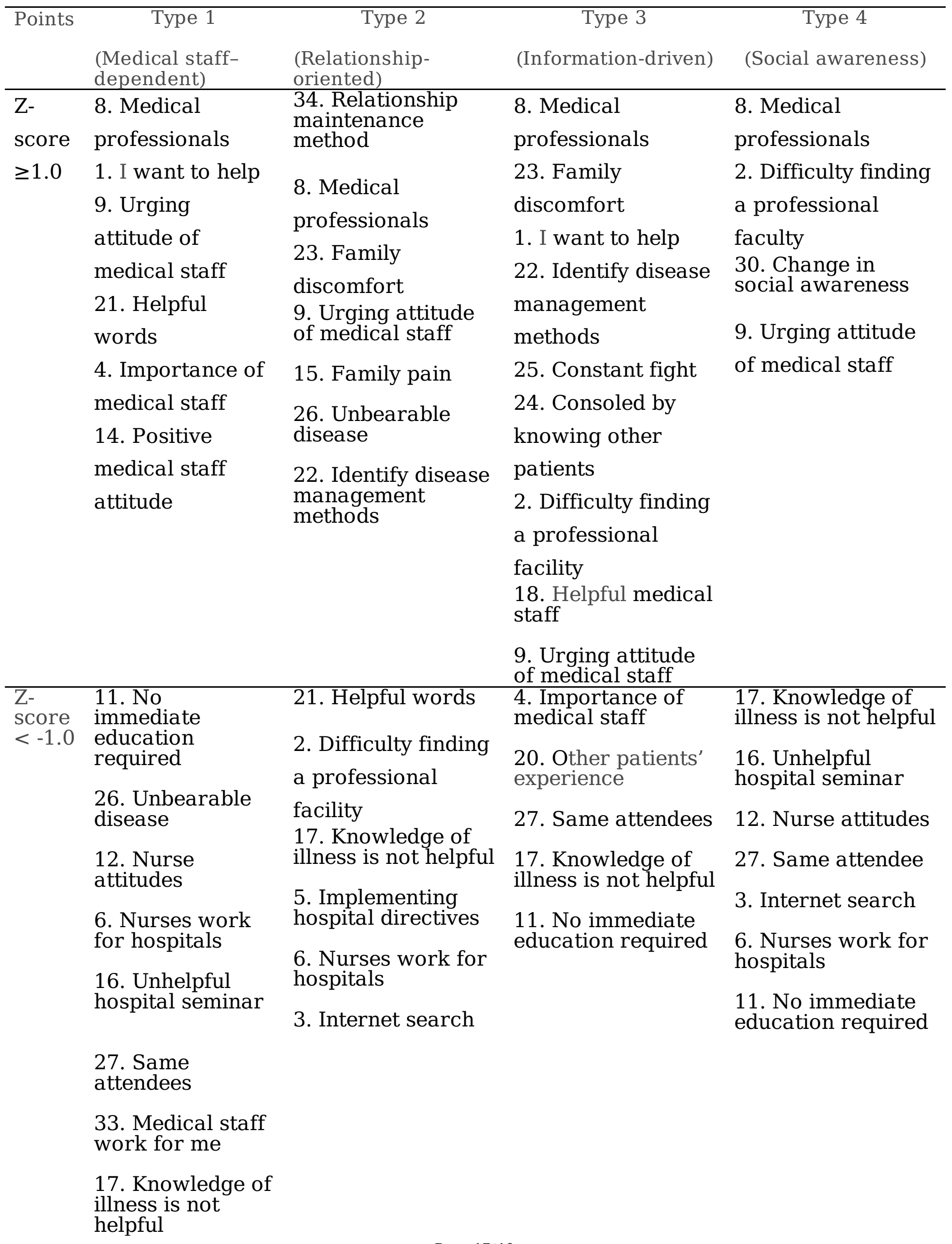




\section{Figures}

1st step: Identifying the concourse

- Literature research

- In-depth interviews

(In-depth interviews of eight IBD patients and family group interviews with three patients and four families conducted in November 2016)

\begin{tabular}{|c|c|c|c|}
\hline \multicolumn{4}{|c|}{ 2nd step: Select Q sample \& Q statement } \\
\hline Q population & Q sample selection & Reliability Verification & $\begin{array}{l}\text { Q Card and Q Distributi } \\
\text { on Map Production }\end{array}$ \\
\hline $\begin{array}{l}274 \text { statements made } \\
\text { through literature } \\
\text { review and previous } \\
\text { research }\end{array}$ & $\begin{array}{l}\text { Selection of } 34 \mathrm{Q} \\
\text { statement }\end{array}$ & $\begin{array}{l}2 \text { experts complete } \\
\text { the Q-sorting within } \\
30 \text { minutes to verify } \\
\text { reliability }\end{array}$ & $\begin{array}{l}\text { Production of card and } \\
\text { distribution map of } \\
\text { selected Q sample } \\
\text { (statement) }\end{array}$ \\
\hline
\end{tabular}

\begin{tabular}{|c|}
\hline 3rd step: P-sampling \\
\hline . Haeundae Paik Hospital 50 outpatients selected as P-sample \\
\hline
\end{tabular}

\begin{tabular}{|c|c|}
\hline \multicolumn{2}{|c|}{ 4th step: Q sorting by Q-grid } \\
\hline Q card sorting & Interview and Q-sorting by Q-grid \\
\hline \begin{tabular}{|l|} 
Classify 34 Q statements by importance on 9- \\
point scale
\end{tabular} \\
\hline \\
\hline 5th step: Analysis (QUANL pc program) and interpreting \\
\hline Factor analysis and characteristic analysis by QUANL program \\
\hline
\end{tabular}

\section{Figure 1}

\section{Q methodology}




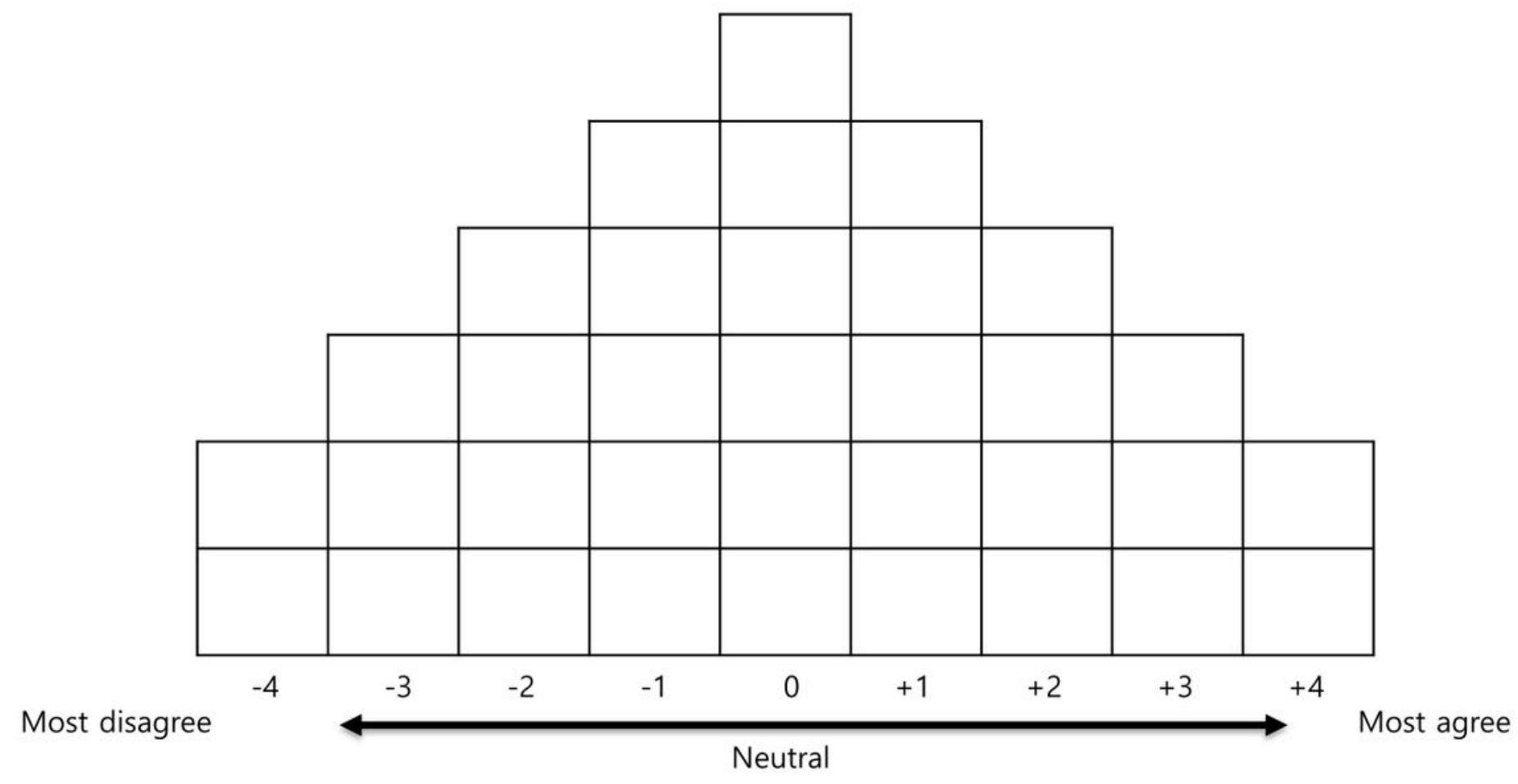

Figure 2

Q- grid

\section{Supplementary Files}

This is a list of supplementary files associated with this preprint. Click to download.

- Supplementarytable1Q.docx 